\title{
Optimization of parameters and operating modes of a biomethane installation for maximum biomethane discharge
}

\author{
Amur Fiapshev ${ }^{1, *}$, Marat Hamokov ${ }^{1}$, Olesya Kilchukova ${ }^{1}$, and Irina Anikina ${ }^{2}$ \\ ${ }^{1}$ Kabardino-Balkarian State Agricultural University named after V. M. Kokov, Lenin Avenue, 1V, \\ 360030 Nalchik, Russia \\ ${ }^{2}$ Toraighyrov University, str. Lomova, 64, 140008 Pavlodar, Republic of Kazakhstan
}

\begin{abstract}
The article covers the results of a theoretical investigation for dung and livestock manure anaerobic fermentation process, substantiated the structural technological scheme and operating modes of the biomethane installation. An investigation complex was carried out on the basis of substantiating the parameters of the technological process, equipment of a biomethane installation, where the goal is to increase the efficiency of substrate processing. Based on the analysis, it was found that the biomethane discharge is one of the main characteristics of processing the substrate, and this moment was taken as the main criterion for optimization work. The rational modes and parameters of the biomethane installation were determined using the mathematical method of planning a multifactorial experiment. The influence of the temperature for the fermentation process of the substrate, the time of mixing the substrate and the number of revolutions of the heat-exchanging mixer on the biogas discharge was established. The influence of design factors, including various factors, was carried out using mathematical statistics and mathematical modeling, where the dependence of the biogas discharge on the temperature of the substrate fermentation process, the time of mixing the substrate and the number of revolutions of the heat exchanging mixer were obtained. The proposed biomethane installation has passed production and laboratory tests in order to optimize the parameters of various capacities for their operation in various regions of the country, the creation of an experimental installation operating in the thermophilic mode, including the stage of preliminary preparation of livestock manure biomass in the technological chain, obtaining liquid and solid fertilizers and other waste-free technology products.
\end{abstract}

\section{Introduction}

The most important role of all human activities that contribute to the transformation of organic substances belongs to agriculture, which, due to the peculiarities of its production is engaged in all the processes accompanying the carbon cycle - the synthesis, destruction and mineralization of organic substances [1-5].

\footnotetext{
${ }^{*}$ Corresponding author: energo.kbr@rambler.ru
} 
Under natural conditions, the rate of methanogenesis under the influence of the anaerobic biocenosis of microorganisms contained in livestock manure or other biomass is low. To intensify the process of methanogenesis, it is necessary to optimize the conditions under which the rate of enzymatic reactions involved in the methane formation would be maximum. An environment in which the concentration of dry matter is at the level of 10$12 \%$ is considered favorable for the life of the biocenosis of methane-forming microorganisms. In this case, the viscosity of the substrate allows the liquid to move freely with suspended solid particles of manure biomass and microbial cells in it, as well as gas bubbles.

Anaerobic fermentation of manure biomass is accompanied by an almost $50 \%$ decrease in the amount of dry organic matter in the sludge compared to its initial level in the reactor due to the inclusion of $10-15 \%$ of the substrate carbon in the microbial biomass, as well as components of biomethane such as methane and carbon dioxide.

The sludge contains less carbon than the original substrate; the presence of potassium and phosphorus gives the sludge the property of a high-quality organic fertilizer, in which nutrients are presented in a form more accessible to plants. The application of sludge into the soil, devoid of the specific odor inherent in processed livestock manure, does not encounter obstacles from an environmental point of view.

The fermented liquid, like the fermented substrate (sludge) does not have an unpleasant odor. This liquid contains $80 \%$ less organic matter, and its biological oxygen demand is $80 \%$ lower than before anaerobic fermentation.

\section{Materials and Methods}

The challenge is to design a high-performance, highly efficient, easy-to-operate and reliable installation.

The research carried out made it possible to design and manufacture an experimental biogas installation with a digester volume of $3.5 \mathrm{~m}^{3}$, operating in the thermophilic mode of anaerobic fermentation, in which the mixing and heating devices are combined into one heat exchanging mixer unit. This technical solution makes it possible to heat the entire mass of the substrate due to the rotation of the heat-exchanging mixer.

\section{Results and Discussion}

To determine the optimal parameters of this installation, experimental investigations were carried out, a matrix of their planning was compiled, criteria of work efficiency and factors influencing them were determined.

To conduct investigations, planning an experiment and compiling a matrix, we set the number of experiments equal to 15 , with the number of factors equal to 3 , are given in table 1.

To analyze the data obtained from experimental investigations, a program for an electronic computing machine was used.

The criterion for evaluating the biomethane installation performance is accepted for biomethane discharge.

Table 1. Experiment planning matrix.

\begin{tabular}{|c|c|c|c|c|c|c|c|c|c|c|c|}
\hline $\mathrm{i}$ & $X_{0}$ & $X_{1}$ & $X_{2}$ & $X_{3}$ & $X_{1}^{2}$ & $X_{2}^{2}$ & $X_{3}^{2}$ & $X_{I}$ & $X_{I}$ & $X_{2}$ & $X_{2}$ \\
$X_{3}$ & $X_{3}$ & $Y_{i}$ \\
\hline 1 & 1 & 1 & 1 & 0 & 1 & 1 & 0 & 1 & 0 & 0 & $Y_{I}$ \\
\hline
\end{tabular}


Table 1. Continued.

\begin{tabular}{|c|c|c|c|c|c|c|c|c|c|c|c|}
\hline 2 & 1 & 1 & -1 & 0 & 1 & 1 & 0 & -1 & 0 & 0 & $Y_{2}$ \\
\hline 3 & 1 & -1 & 1 & 0 & 1 & 1 & 0 & -1 & 0 & 0 & $Y_{3}$ \\
\hline 4 & 1 & -1 & -1 & 0 & 1 & 1 & 0 & 1 & 0 & 0 & $Y_{4}$ \\
\hline 5 & 1 & 0 & 0 & 0 & 0 & 0 & 0 & 0 & 0 & 0 & $Y_{5}$ \\
\hline 6 & 1 & 1 & 0 & 1 & 1 & 0 & 1 & 0 & 1 & 0 & $Y_{6}$ \\
\hline 7 & 1 & 1 & 0 & -1 & 1 & 0 & 1 & 0 & -1 & 0 & $Y_{7}$ \\
\hline 8 & 1 & -1 & 0 & 1 & 1 & 0 & 1 & 0 & -1 & 0 & $Y_{8}$ \\
\hline 9 & 1 & -1 & 0 & -1 & 1 & 0 & 1 & 0 & 1 & 0 & $Y_{9}$ \\
\hline 10 & 1 & 0 & 0 & 0 & 0 & 0 & 0 & 0 & 0 & 0 & $Y_{10}$ \\
\hline 11 & 1 & 0 & 1 & 1 & 0 & 1 & 1 & 0 & 0 & 1 & $Y_{11}$ \\
\hline 12 & 1 & 0 & 1 & -1 & 0 & 1 & 1 & 0 & 0 & -1 & $Y_{I 2}$ \\
\hline 13 & 1 & 0 & -1 & 1 & 0 & 1 & 1 & 0 & 0 & -1 & $Y_{13}$ \\
\hline 14 & 1 & 0 & -1 & -1 & 0 & 1 & 1 & 0 & 0 & 1 & $Y_{I 4}$ \\
\hline 15 & 1 & 0 & 0 & 0 & 0 & 0 & 0 & 0 & 0 & 0 & $Y_{I 5}$ \\
\hline
\end{tabular}

Theoretical investigations of the biomethane installation operation showed that the biomethane productivity is influenced by the following factors: temperature of the substrate fermentation process $T_{C}$; mixer revolutions $n_{T}$ and substrate $t_{\Pi}$ mixing time are presented in table 2 .

Table 2. Levels and factors of their variation.

\begin{tabular}{|c|c|c|c|c|}
\hline \multirow{2}{*}{$\begin{array}{c}\text { Varying } \\
\text { factors } \\
\text { step and } \\
\text { levels }\end{array}$} & \multirow{2}{*}{$\begin{array}{c}\text { Coded value of } \\
\text { factors } \\
\text { (dimensionless) }\end{array}$} & $\begin{array}{c}|c| \\
\left(T_{c},\right. \\
\text { degree })\end{array}$ & $\begin{array}{c}\mathrm{X} 2 \\
\left(t_{I I}, \mathrm{~min}\right)\end{array}$ & $\begin{array}{c}\mathrm{X} 3 \\
\left(n_{T}, \mathrm{rpm}\right)\end{array}$ \\
\hline Step & - & 3 & 3 & 0.5 \\
\hline Low & -1 & 54 & 14 & 7 \\
\hline Zero & 0 & 57 & 17 & 7.5 \\
\hline Upper & +1 & 60 & 20 & 8 \\
\hline
\end{tabular}

In order to determine the optimal parameters and operating modes of the biogas installation, a regression equation was drawn up:

$$
\begin{aligned}
& Y_{Q_{E T}}=15,3967-0,6838 X_{1}+0,0925 X_{2}-0,2888 X_{3}-0,27 X_{1} X_{2}- \\
& -0,7725 X_{1} X_{3}+0,775 X_{2} X_{3}-1,2996 X_{1}^{2}-1,0471 X_{2}^{2}-1,1196 X_{3}^{2} .
\end{aligned}
$$

According to Fisher's criterion, the adequacy of the equation

$$
\left(F_{\text {design }}=0.765<F_{\text {table }}=2.359\right) \text {. }
$$

The regression equation (1) in the decoded form is as follows: 


$$
\begin{aligned}
& Q_{6 \Gamma}=15,3967-0,6838\left(\frac{T_{\Pi}-57}{3}\right)+0,0925\left(\frac{t_{\Pi}-17}{3}\right)-0,2888\left(\frac{n_{T}-7,5}{0,5}\right)-0,27\left(\frac{T_{\Pi}-57}{3}\right) . \\
& \cdot\left(\frac{t_{\Pi}-17}{3}\right)-0,7725 \cdot\left(\frac{T_{\Pi}-57}{3}\right)\left(\frac{n_{T}-7,5}{0,5}\right)+0,775\left(\frac{t_{\Pi}-17}{3}\right)\left(\frac{n_{T}-7,5}{0,5}\right)-1,2996\left(\frac{T_{\Pi}-57}{3}\right)^{2}- \\
& -1,0471\left(\frac{t_{\Pi}-17}{3}\right)^{2}-1,1196\left(\frac{n_{T}-7,5}{0,5}\right)^{2}
\end{aligned}
$$

Equation (2) after transformations shall take the following form:

$$
\begin{aligned}
& Q_{Б \Gamma}=-905,8499+20,6062 T_{\Pi}+1,8215 t_{\Pi}+87,1701 n_{T}-0,03 T_{\Pi} t_{\Pi}- \\
& -0,515 T_{\Pi} n_{T}+0,5167 t_{\Pi} n_{T}-0,1444 T_{\Pi}^{2}-0,1163 t_{\Pi}^{2}-4,4784 n_{T}^{2} .
\end{aligned}
$$

Compiled system of differential equations (1), representing partial derivatives with respect to three factors, in order to establish the values of the factors for the maximum biomethane discharge.

$$
\left\{\begin{array}{l}
\frac{d Y_{Q_{D T}}}{d t}=-0,6838-0,27 X_{1}-0,7725 X_{3}-2,5992 X_{1}=0 \\
\frac{d Y_{Q_{D T}}}{d t}=0,0925-0,27 X_{1}+0,775 X_{3}-2,0942 X_{2}=0 \\
\frac{d Y_{Q_{D T}}}{d t}=-0,2888-0,7725 X_{1}+0,775 X_{2}-2,2392 X_{3}
\end{array} .\right.
$$

The optimal values of the factors in the coded form are determined as a result of solving the system of equations (4):

$$
X_{1}=-0,2519 ; X_{2}=0,0014 ; X_{3}=-0,0381 \text {. }
$$

The maximum methane discharge is $15.5 \mathrm{~m}^{3} /$ day is achieved with decoded values of the factors: the number of revolutions of the heat-exchanging mixer - $7.5 \mathrm{rpm}$; mixing time of the substrate -17 minutes; the temperature of the substrate fermentation process $-56.2{ }^{\circ} \mathrm{C}$.

The experiment reproducibility was checked according to the Cochran criterion:

$$
G_{\text {pacu }}=S^{2}\left(y_{i}\right)_{M A X} / \sum_{i=1}^{N} S^{2}\left(y_{i}\right)=0,3003
$$

The table value of the Cochran test is $G_{t a b l e}=0.335$ at a $5 \%$ significance level $f_{1}=2$, $f_{2}=15$. The hypothesis about the homogeneity of variances is confirmed, since the value of the calculated Cochran criterion is less than the tabular one.

At zero temperature of the process of substrate fermentation $\left(T_{\Pi}=57^{\circ} \mathrm{C}\right)$, the regression equation has the form:

$$
Q_{5 \Gamma}=-200,4522+0,1115 t_{\Pi}+57,8151 n_{T}+0,5167 t_{\Pi} n_{T}-0,1163 t_{I I}^{2}-4,4784 n_{T}^{2} .
$$

Figure 1 shows the response surface for these characteristics. 
At zero time of the process of substrate fermentation $\left(t_{\Pi}=17 \mathrm{~min}\right)$, the regression equation has the form:

$$
Q_{\text {LT }}=-908,4952+20,0962 T_{\Pi}+95,954 n_{T}-0,515 T_{\Pi T} n_{T}-0,1444 T_{\Pi}^{2}-4,4784 n_{T}^{2} .
$$

Figure 2 shows the response surface for these characteristics.

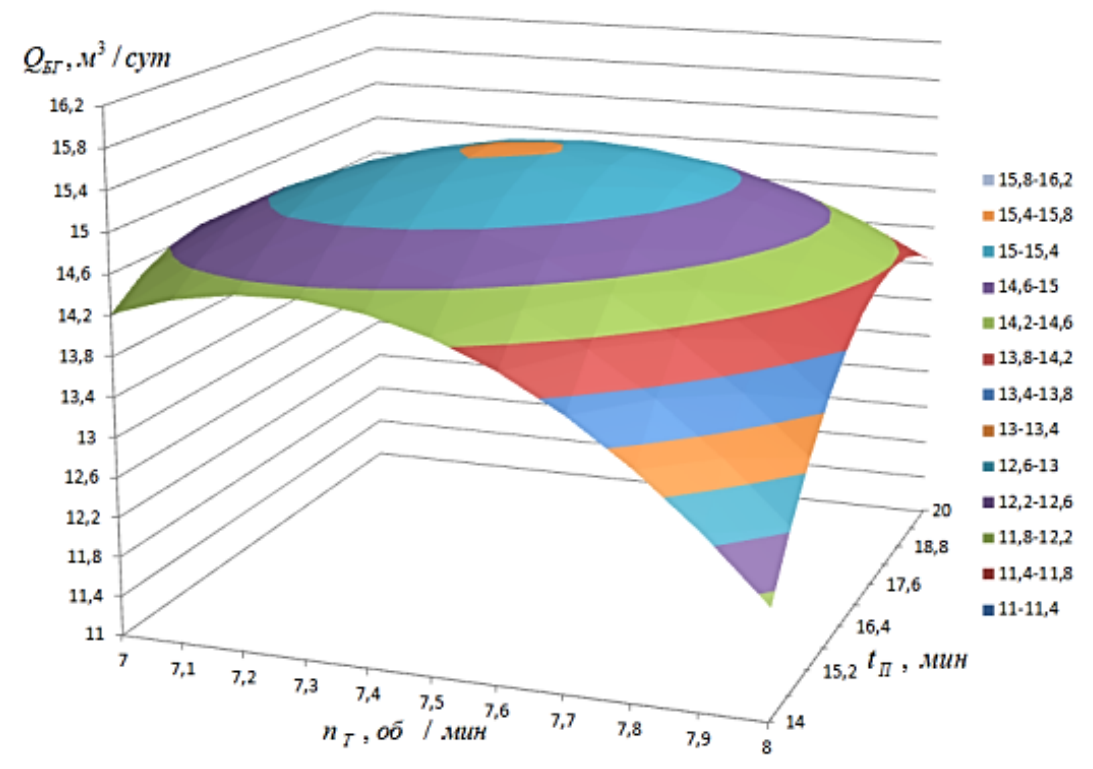

Fig. 1. Response surface $f\left(T_{\Pi}, n_{T}\right)$ at zero level $T_{\Pi}=57^{\circ} \mathrm{C}$.

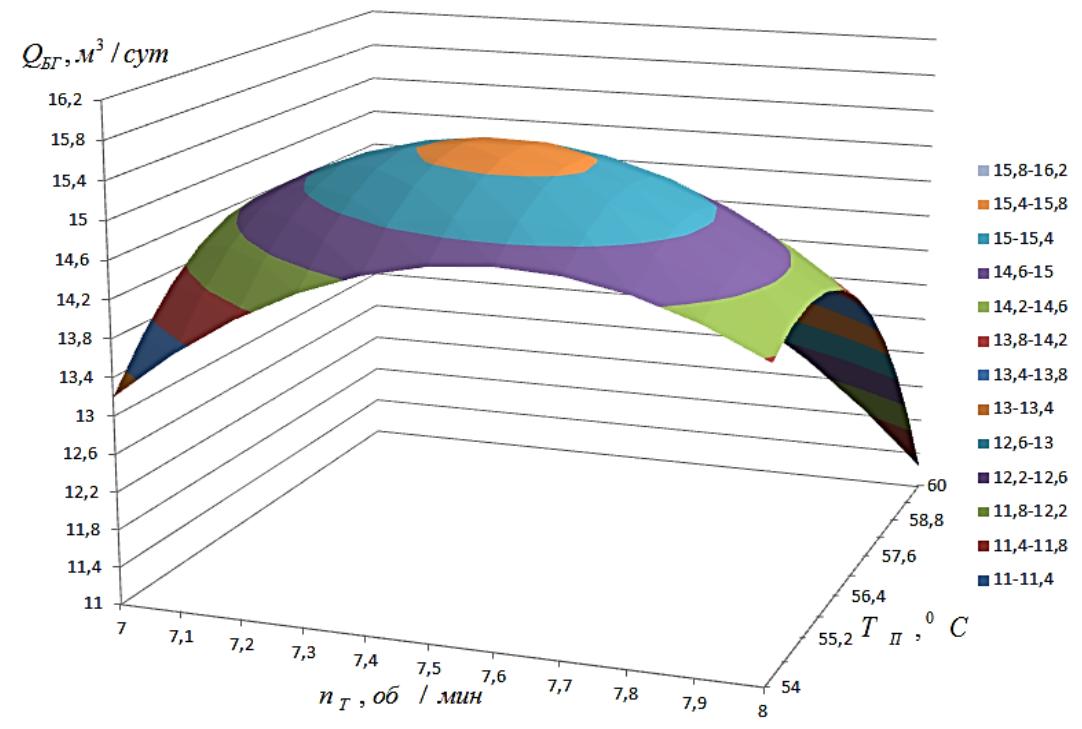

Fig. 2. Response surface at zero level $=17 \mathrm{~min}$.

At zero revolutions of the heat-exchanging mixer $\left(n_{T}=7.5 \mathrm{rpm}\right)$, the regression equation has the form: 


$$
Q_{b \Gamma}=-503,9842+16,7737 T_{\Pi}+5,6967 t_{\Pi}-0,03 T_{\Pi} t_{\Pi}-0,1444 T_{\Pi}^{2}-0,1163 t_{\Pi}^{2}
$$

Figure 3 shows the response when these characteristics change.

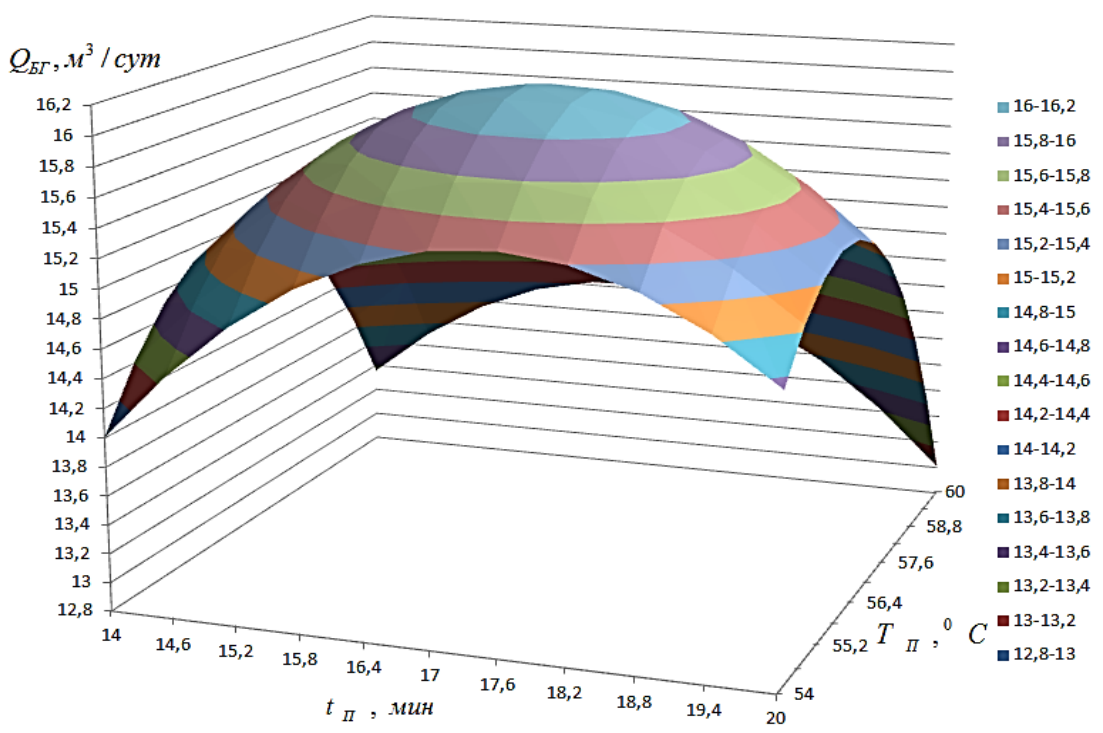

Fig. 3. Response surface $f\left(T_{\Pi}, n_{T}\right)$ at zero level $n_{T}=7.5 \mathrm{rpm}$.

\section{Conclusions}

The conducted investigations allow us to conclude that the maximum value of the optimization criterion (biomethane discharge) $15.5 \mathrm{~m}^{3} /$ day is achieved with the values of varying factors: temperature of the substrate fermentation process $T_{\Pi}=56,2^{\circ} \mathrm{C}$; mixing time of the substrate, $t_{\Pi}=17 \mathrm{~min}$; a number of revolutions of the heat-exchanging mixer $n_{T}=7,5 \mathrm{rpm}$.

\section{References}

1. A. K. Apazhev, Y. A. Shekikhachev, A. G. Fiapshev, L. M. Hazhmetov, E3S Web of Conferences, International Scientific and Technical Conference Smart Energy Systems 2019 (SES-2019), 124, 05054 (2019)

2. A. K. Apazhev, Energy Saving and Energy Efficiency: Problems and Solutions, 8-11 (2020)

3. A. K. Apazhev, Actual problems of agricultural science: applied and research aspects, 1, 14-17 (2021)

4. A. K. Apazhev, Y. A. Shekikhachev, V. I. Batyrov, Kh. L. Gubzhokov, A. L. Bolotokov, IOP Conference Series: Materials Science and Engineering, 663(1), 012049 (2019)

5. A. K. Apazhev, Y. A. Shekikhachev, L. M. Hazhmetov, Z. L. Hazhmetova, D. T. Gabachiyev, J. of Physics: Conference Series, 1399(5), 055002 (2019) 
6. I. M. Khaniyeva S.A. Bekuzarova, A. K. Apazhev, Bioenergetic assessment of crop cultivation technologies and calculation of the economic efficiency of fertilization (2019)

7. A. K. Apazhev, M. A. Marzhohova, L. Z. Halishkhova, The Phenomenon of Sustainability of Economic and Environmental Development of Agrarian Territories (2015)

8. A. K. Apazhev, Ts. B. Kagermazov, M. K. Kozhokov, A. S. Gordeyev, M. M. Kushkhova, Agrarian Russia, 1, 39-42 (2015)

9. A. Fiapshev, O. Kilchukova, Y. Shekikhachev, M. Khamokov, L. Khazhmetov, MATEC Web of Conf., 212, 01032 (2018)

10. A. K. Apazhev, Y. A. Shekikhachev, A. G. Fiapshev, O. Kh. Kilchukova, Int. scientific and practical conference «AgroSMART - Smart solutions for agriculture», KnE Life Sciences, 40-50 (2019)

11. A. K. Apazhev, Yu. A. Shekikhachev, L. M. Khazhmetov, A. G. Fiapshev, A. B. Baragunov, M. M. Khamokov, O. H. Kilchukova, Bulletin of Agricultural Consulting, 4, 42 (2015)

12. A. K. Apazhev, Yu. A. Shekikhachev, A. G. Khazhmetov, Bulletin of the Gorsky State Agricultural University, 11 (2), 60-63 (2016)

13. A. G. Fiapshev, M. M. Khamokov, O. Kh. Kilchukova, J. of Physics: Conference Series (JPCS), 1679, 052074 (2020) 